\title{
Temperature and Water Stress Integral Influence in Physiological Responses among Eucalyptus Genotypes +
}

\author{
Thiago Wendling Gonçalves de Oliveira ${ }^{1, *}$, Rafael Rubilar ${ }^{2}$, Ana Paula Dalla Corte ${ }^{1}$ and \\ Carlos Roberto Sanquetta ${ }^{1}$ \\ 1 Department of Forest Science, Federal University of Parana, Pref. Lothário Meissner Avenue, 900, \\ 80210-170 Curitiba, Paraná State, Brazil; anapaulacorte@gmail.com (A.P.D.C.); \\ carlossanquetta@gmail.com (C.R.S.) \\ 2 Forest Productivity Cooperative, Faculty of Forestry, University of Concepcion, Calle Victoria, 500 \\ Concepción, Bio-Bio, Chile; rafaelrubilar@gmail.com \\ * Correspondence: thiago.wgdeolivera@gmail.com; Tel.: +55-41-98858-2031 \\ + Presented at the 1st International Electronic Conference on Plant Science, 1-15 December 2020; Available \\ online: https://iecps2020.sciforum.net/.
}

Published: 30 November 2020

\begin{abstract}
Water stress is expected to reduce photosynthesis and leaf water potential to regulate plant water use efficiency. We hypothesized that higher summer temperatures increase photosynthesis and decrease water use, which are more pronounced in more stressed genotypes. This study investigated photosynthesis (An), stomatal conductance (gs), and water stress integral (WSI) changes in the early development of E. globulus, E. nitens, and E. nitens $\times$ E. globulus hybrids during winter and summer. An, gs, and WSI showed a significant interaction $(p>0.001)$ between genotype and season. Regardless of the season, E. globulus showed no significant changes in An, while higher increase was observed in E. gloni $(50 \%)$ in summer. There was an increment in gs between the seasons $(167 \%)$, which was more pronounced in E. nitens $(300 \%)$. This implied significant changes between species and seasons for iWUE. The lowest iWUE in summer was related to the lowest WSI, with E. nitens being different from other taxa $(p=0.01)$. We observed a positive relationship between WSI and iWUE in summer, but negative in winter. The results suggest that WSI in winter helps to promote stomatal closure, which increases iWUE, since An presented small changes. Regardless of genotype, warm periods increased An and decreased iWUE, which imply different strategies of eucalyptus plantations in regions with water deficit.
\end{abstract}

Keywords: forest management; forest physiology; water use efficiency

\section{Introduction}

Increased productivity of eucalyptus plantations has been achieved by the combination of silvicultural improvements and forest breeding, with selection of specific genotypes for adequate sites [1,2]. Selection of eucalyptus genotypes, such as Mediterranean eucalyptus species, requires knowledge on how they will be affected by the seasons (temperature and vapor pressure deficit (VPD)) or site availability throughout the year [3-5].

Breeding of trees that are tolerant of higher environmental changes may be a promising approach, but it requires knowledge on physiological mechanisms during plant development [6]. Short-term responses to avoid water and heat stress include higher water potential maintenance, carbon assimilation reduction, and stomatal closure [7]. Changes in photosynthesis and water use efficiency have been identified as key parameters for evaluating eucalyptus adaptation to 
environmental constraints, such as water deficit and higher atmospheric demand [8]. However, researchers need to establish experiments in the field to determine the effects of physiological variables on plant development [9].

Our study investigated the genotype $\times$ season physiological responses of 12 high productivity eucalyptus genotypes in two seasons in Chile. We evaluated that regardless of genotype, with the increase in temperature in summer, changes in photosynthetic rates will be greater than in winter; however, the increase in atmospheric demand (VPD) leads to a decrease in intrinsic water use efficiency, and genotypes that present the highest absolute water stress integral will be the least efficient in water use.

\section{Experiments}

\subsection{Site Characteristics}

The experiment was established $9.6 \mathrm{~km}$ east of Yumbel town in central South Chile (37 $80.01 \mathrm{~S}$, $\left.72^{\circ} 27^{\prime} 34.70^{\prime \prime} \mathrm{W}\right)$. Soils are Entisols, formed by black volcanic sands of andesitic and basaltic origin with low water holding capacity. The Köppen classification is a warm-summer Mediterranean climate with winter rains (Csb). The average annual precipitation at the site was $1328 \mathrm{~mm}$, occurring mainly in winter $(600 \mathrm{~mm})$, with $60 \mathrm{~mm}$ in summer. The mean annual temperature was $14.2{ }^{\circ} \mathrm{C}$, with maximum temperature in January $\left(38.9^{\circ} \mathrm{C}\right)$ and minimum temperature in July $\left(-1.7^{\circ} \mathrm{C}\right)$. Solar radiation ranges from $10.4 \mathrm{MJ} \mathrm{m}^{-2}$ day $^{-1}$ in July, during winter, to $29.3 \mathrm{MJ} \mathrm{m}^{-2}$ day $^{-1}$ in January, during summer.

\subsection{Experimental Design and Treatments}

Considering 12 higher productivity eucalyptus genotypes, a completely randomized block design with three replicates was done in October 2017. Five genotypes were Eucalyptus globulus Labill (EG 17, EG 18, EG 21, EG 30, and EG 31), two were E. nitens H. Deane \& Maiden (EN 13 and EN 14), and five were E. nitens $\times$ E. globulus (E. gloni) hybrids (ENG 2, ENG 3, ENG 4, ENG 5, and ENG 8). In this study, seedlings with no visual disease symptoms or damage were selected. Experimental units were established by hand planting 16 plants $\left(24 \mathrm{~m}^{2}\right)$. Plant spacing was $1.5 \mathrm{~m}^{2}\left(6667\right.$ trees ha- $\left.{ }^{-1}\right)$ in order to accelerate any response of canopy closure and intraspecific competition. After one month, replanting was done to maintain homogeneous conditions across the experiment. Herbicides were used to keep the plants weed-free, and controlled-release fertilizer was used to keep plants without nutritional deficiency. To ensure survival, irrigation was applied from the planting time until March 2018 (first dry summer season), and from the end of November 2018 until mid-February 2019 (second dry summer season).

\subsection{Physiological Measurements}

Physiological variables were evaluated in four periods: early winter 2018 (12 June), mid-winter 2018 (8 August), early summer 2018 (14 December), and mid-summer 2019 (18 February). These dates coincided with different periods of temperature and VPD at the experiment site.

Predawn leaf water potential $\left(\Psi_{\mathrm{pd}}\right)$ was measured using a Scholander pressure chamber (PMS Instruments, Corvallis, OR, USA). Measurements were made in one plant per plot, in mature, fully expanded, and sun-exposed leaves of the upper canopy between 4:00 and 6:00 h. Following Myers [10], we calculated the total water stress integral (WSI) as the cumulative integral of predawn leaf water potential $\left(\Psi_{\mathrm{pd}}\right)$ over the entire period of mensuration:

$$
W S I=\sum_{i=0}^{t}\left(\bar{\Psi}_{i, i+1}-c\right) * n
$$

where $\bar{\Psi}_{i, i+1}$ is the mean $\Psi_{\mathrm{pd}}$ for interval $i, i+1$, and $c$ is the maximum value of $\Psi_{\mathrm{pd}}$ during the measurements, and $n$ is the number of days at interval $i, i+1$.

Leaf gas exchange measurement included net $\mathrm{CO}_{2}$ assimilation rate $\left(\mathrm{An}, \mu \mathrm{mol} \mathrm{CO}_{2} \mathrm{~m}^{-2} \mathrm{~s}^{-1}\right)$ and stomatal conductance ( $\mathrm{gs}, \mathrm{mol} \mathrm{H}_{2} \mathrm{O} \mathrm{m}^{-2} \mathrm{~s}^{-1}$ ). Measurements were done in one plant per plot, in mature, fully expanded, and sun-exposed leaves using a portable infrared gas analyzer LICOR-6400 (Li-Cor, 
Inc., Lincoln, NE, USA). All measurements were done with reference $\mathrm{CO}_{2}$ at $400 \mu \mathrm{mol}^{\mathrm{mol}}{ }^{-1}$, light intensity (PAR) in the leaf chamber at $1500 \mu \mathrm{mol} \mathrm{m}^{-2} \mathrm{~s}^{-1}$, constant flow rate of $500 \mu \mathrm{mol} \mathrm{s} \mathrm{s}^{-1}$, and leaf temperature (Tleaf) of $20^{\circ} \mathrm{C}$. Intrinsic water use efficiency (iWUE, $\mu \mathrm{mol} \mathrm{CO}_{2} \mathrm{~mol}^{-1} \mathrm{H}_{2} \mathrm{O}$ ) was calculated using the ratio of An and gs.

\subsection{Statistical Analysis}

Analysis of variance (ANOVA) was used on the differences in WSI, An, gs, and iWUE in different seasons and genotypes. Seasons and genotypes were considered fixed effects, and blocks were considered random effects. All ANOVA analyses were performed using the MIXED procedure. Differences in WSI, An, gs, and iWUE were determined with the LSMEANs statement using the Tukey-Kramer adjustment $(p<0.05)$. A Michalis-Menten model was fitted to evaluate the relationship between An and gs throughout the seasons, considering all genotypes and individual taxa. Regression analysis was used in the GLM procedure to assess the relationship between iWUE and WSI at taxa level. Analyses were performed using SAS ${ }^{\circledR}$ Studio (https://www.sas.com/en_us/software/studio.html). All graphical analyses were performed in $\mathrm{R}$ software using the ggplot2 package [11].

\section{Results}

\subsection{Climate Data}

Temperature presented a narrow range in winter periods, with a minimum close to $0{ }^{\circ} \mathrm{C}$ and maximum below $12^{\circ} \mathrm{C}$; a wider range was observed during summer, with a minimum below $10^{\circ} \mathrm{C}$ and maximum above $20^{\circ} \mathrm{C}$ (Figure 1a). VPD ranges from 0.02 to $0.30 \mathrm{kPa}$ in winter periods. The minimum VPD remained constant throughout the year, but the maximum VPD was almost $3.00 \mathrm{kPa}$ in mid-summer, increasing the VPD range in warm periods (Figure 1b).

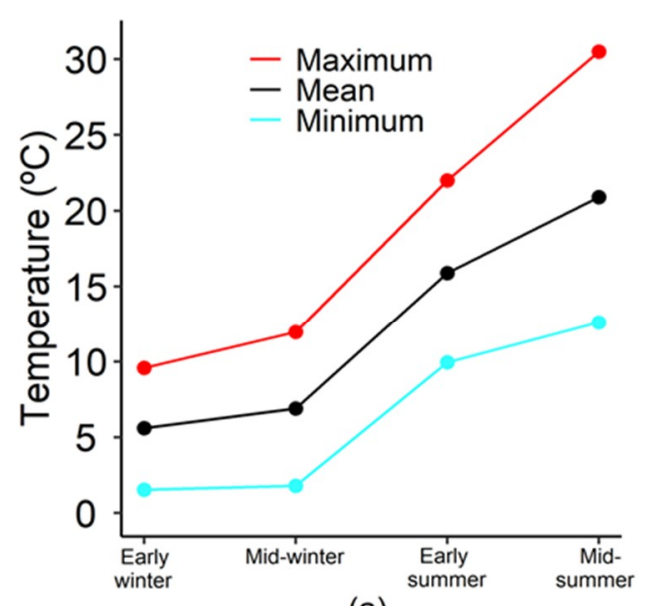

(a)

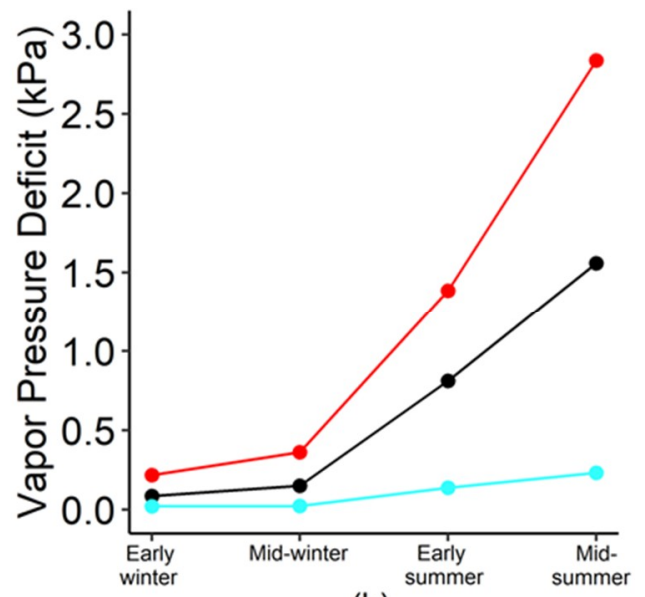

(b)

Figure 1. (a) Air temperatures and (b) vapor pressure deficit during the measurement periods.

\subsection{Physiology}

Season $\times$ genotype had significant effects on all physiological variables (An, gs, iWUE, and WSI) $(p<0.001)$ (Table 1). Across all genotypes in winter, small changes $(>15 \%)$ were observed in the average values of An and iWUE, but the average WSI decreased by $31 \%$. In summer, large changes in physiological variables were observed between early and mid-summer; An increased by $27 \%$, while iWUE and WSI decreased by $85 \%$ and $27 \%$, respectively. 
Table 1. ANOVA $p$-values on season, genotype, and interaction effects on photosynthesis (An), stomatal conductance (gs), intrinsic water use efficiency (iWUE), and water stress integral (WSI).

\begin{tabular}{ccccc}
\hline Effect & An & gs & iWUE & WSI \\
\hline Seasons & $<0.001$ & $<0.001$ & $<0.001$ & $<0.001$ \\
Genotype & $<0.001$ & $<0.001$ & $<0.001$ & $<0.001$ \\
Seasons $\times$ Genotype & $<0.001$ & $<0.001$ & $<0.001$ & $<0.001$ \\
\hline
\end{tabular}

The lowest and highest average values of An were in similar periods among taxa. The lowest average An was in early-summer for E. globulus $\left(14.99 \mu \mathrm{mol} \mathrm{CO} \mathrm{m}^{-2} \mathrm{~s}^{-1}\right)$, for E. nitens $(14.06 \mu \mathrm{mol}$ $\left.\mathrm{CO}_{2} \mathrm{~m}^{-2} \mathrm{~s}^{-1}\right)$, and for E. gloni $\left(12.97 \mu \mathrm{mol} \mathrm{CO} 2 \mathrm{~m}^{-2} \mathrm{~s}^{-1}\right)$. The highest average An was in mid-summer for E. globulus $\left(17.43 \mu \mathrm{mol} \mathrm{CO} \mathrm{m}^{-2} \mathrm{~s}^{-1}\right)$, E. nitens $\left(18.81 \mu \mathrm{mol} \mathrm{CO} \mathrm{Cm}^{-2} \mathrm{~s}^{-1}\right)$, and E. gloni $(20.60 \mu \mathrm{mol}$ $\left.\mathrm{CO}_{2} \mathrm{~m}^{-2} \mathrm{~s}^{-1}\right)$. Between early and mid-summer, the lowest changes in An was observed in E. globulus $(+12 \%)$, and the largest changes in E. nitens $(+26 \%)$ and E. gloni $(+37 \%)$. The higher average gs was observed in mid-summer for E. globulus $\left(0.59 \mathrm{~mol} \mathrm{H}_{2} \mathrm{O} \mathrm{m}^{-2} \mathrm{~s}^{-1}\right)$, E. nitens $\left(0.65 \mathrm{~mol} \mathrm{H}_{2} \mathrm{O} \mathrm{m}^{-2} \mathrm{~s}^{-1}\right)$, and $\mathrm{E}$. gloni $\left(0.61 \mathrm{~mol} \mathrm{H}_{2} \mathrm{O} \mathrm{m}^{-2} \mathrm{~s}^{-1}\right)$. Lower changes in gs were during winter $(-7 \%)$, but in summer there was an increased in gs values for all genotypes, with average increment of $57 \%$. We observed similar behavior in An and gs of eucalyptus genotypes throughout the seasons. Summer changes in gs were higher than summer changes in An, so we expect that lower values of iWUE in summer compare to winter.

We observed a positive relationship between An and gs, suggesting that An variation could be predicted by gs across seasons and taxa. The Michaelis Menten (MM) model was used to check this relationship (Figure 2). Full versus reduced model comparisons of MM for season effects showed that for all genotypes, season was significant $(\mathrm{F}=25.52, p<0.001)$. Season comparison for individual taxa showed significant effects in E. globulus $(\mathrm{F}=4.41, p<0.017)$, E. nitens $(\mathrm{F}=28.02, p<0.001)$, and E. gloni $(\mathrm{F}=11.29, p<0.001)$. The $\mathrm{b}$ parameters of the models represent the mean gs value, of which half of maximum An (a parameter) was attained (Table 2). In general, the models showed better fits for summer than winter. Only E. nitens and E. gloni in winter showed non-significance for the $b$ parameter, which suggested that a maximum mean value was able to represent An in these taxa.

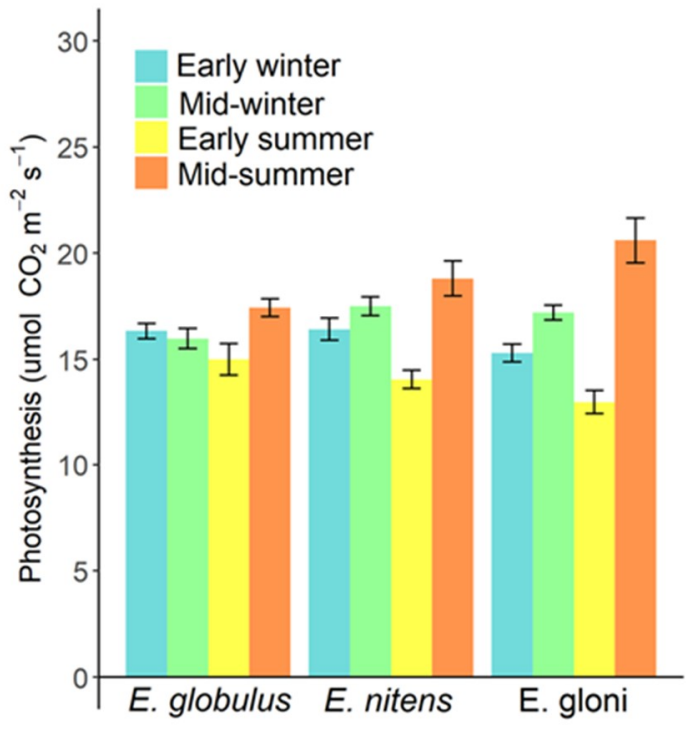

(a)

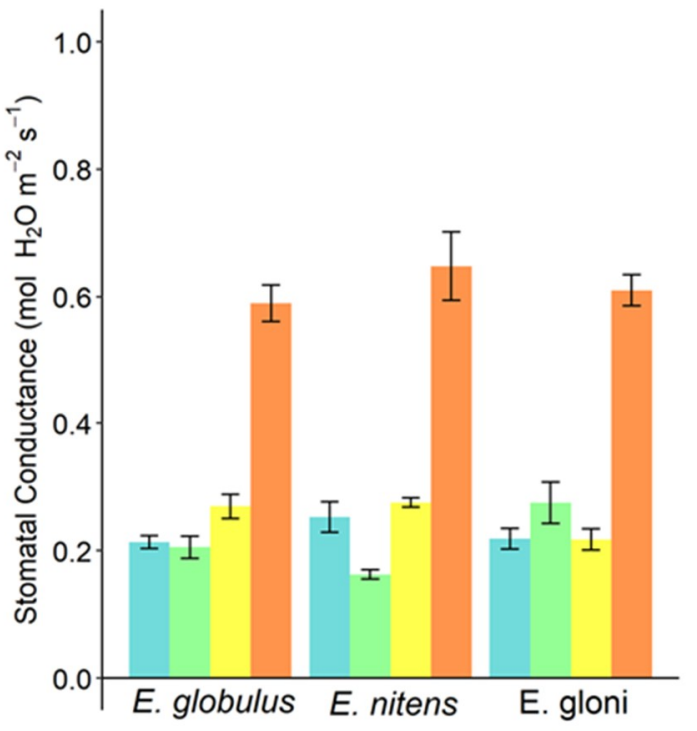

(b)

Figure 2. (a) Mean photosynthesis (An) and (b) mean stomatal conductance (gs) for eucalyptus taxa and seasons. Vertical bars correspond to standard error of taxa means. 


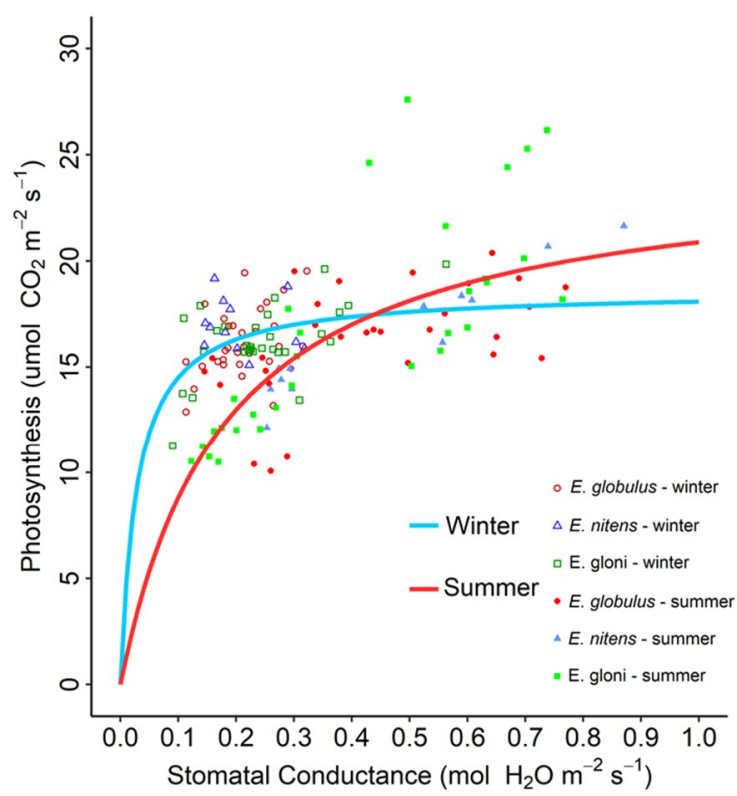

(a)

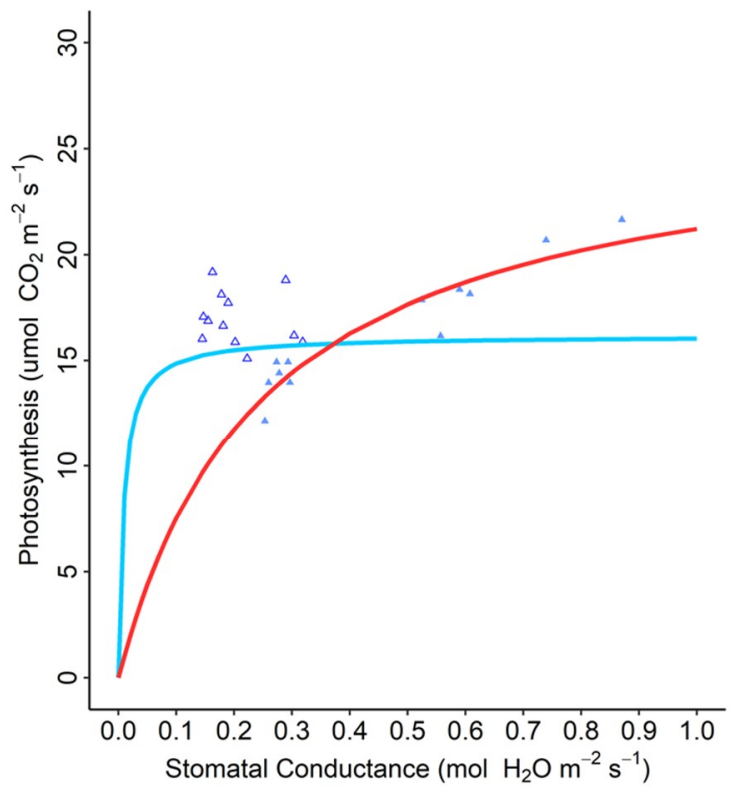

(c)

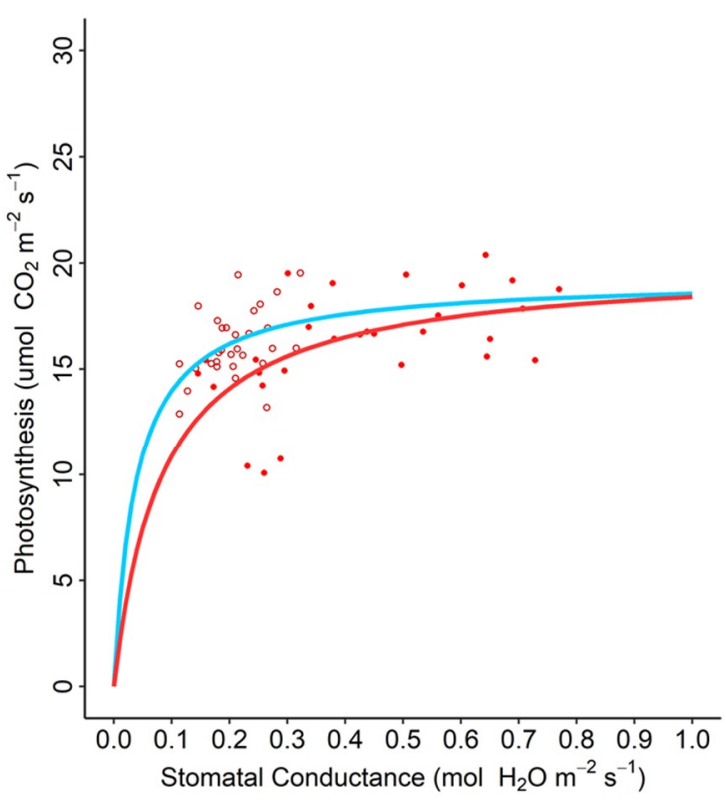

(b)

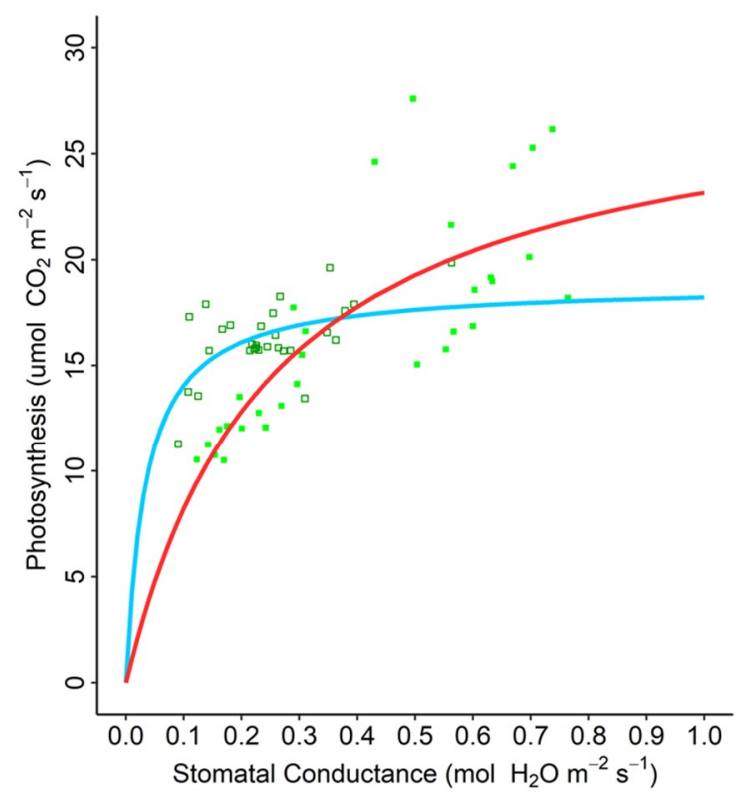

(d)

Figure 2. MM models adjusted for gs and An relationship for winter and summer for (a) all, (b) E. globulus, (c) E. nitens, and (d) E. gloni genotypes.

Table 2. MM models adjusted for gs and An relationship for all genotypes and individual taxa ( $E$. globulus, E. nitens, and E. gloni) that showed significant effects of seasons (winter and summer). MM models are represented by the expression $\mathrm{An}=\mathrm{a}^{*} \mathrm{gs} /(\mathrm{b}+\mathrm{gs})$ and goodness of fit of models was evaluated by root mean square error (RSME) and pseudo- $\mathrm{R}^{2}$ values.

\begin{tabular}{cccccc}
\hline \multirow{2}{*}{ Model } & \multirow{2}{*}{ Effects } & \multicolumn{2}{c}{ Parameters } & \multirow{2}{*}{ RMSE } & \multirow{2}{*}{$\mathbf{R}^{2}$} \\
\cline { 3 - 6 } All genotypes & Winter \& Summer & $20.491^{*}$ & $0.085^{*}$ & 2.47 & 0.28 \\
& Winter & $18.597^{*}$ & $0.028^{*}$ & 1.44 & 0.21 \\
& Summer & $24.624^{*}$ & $0.179^{*}$ & 2.61 & 0.52 \\
\hline \multirow{2}{*}{ E. globulus } & Winter \& Summer & $18.319^{*}$ & $0.034^{*}$ & 1.95 & 0.16
\end{tabular}




\begin{tabular}{cccccc} 
& Winter & $19.251 *$ & $0.038^{*}$ & 1.4 & 0.21 \\
& Summer & $19.927^{*}$ & $0.083^{*}$ & 2.14 & 0.30 \\
\hline \multirow{2}{*}{ E. nitens } & Winter \& Summer & $18.189 *$ & $0.023^{*}$ & 2.09 & 0.07 \\
& Winter & $16.181 *$ & $0.009 \mathrm{~ns}$ & 1.19 & 0.03 \\
& Summer & $26.580^{*}$ & $0.253^{*}$ & 0.93 & 0.89 \\
\hline \multirow{2}{*}{ E. gloni } & Winter \& Summer & $23.818^{*}$ & $0.119^{*}$ & 2.75 & 0.45 \\
& Winter & $18.834^{*}$ & $0.034 \mathrm{~ns}$ & 1.41 & 0.32 \\
& Summer & $29.024^{*}$ & $0.253^{*}$ & 2.97 & 0.64 \\
\hline
\end{tabular}

ns $=$ not significant, ${ }^{*} p<0.05$.

Interestingly, summer showed higher gs values to attain their maximum An for all taxa. Because of higher gs values in winter, iWUE was lower than in summer. The ratio of $a$ and $b$ parameters represents the slope of iWUE relationship, ranked E. nitens $>$ E. gloni $>$ E. globulus in winter, and E. globulus $>$ E. gloni $>$ E. nitens in summer. E. nitens genotypes were that presented the highest reduction in average iWUE values (300\%).

Full versus reduced model comparison of generalized linear model for season effects was significant $\left(\mathrm{F}=35.14, p>0.001, \mathrm{R}^{2}=0.43\right)$. We observed a significant interaction between absolute WSI and season $(\mathrm{F}=9.98, p>0.001)$, because the direction of the relationship between these variables changed with seasons. In winter, we observed a positive correlation between absolute WSI and iWUE $($ iWUE $=67.742+0.268 *$ WSI), where genotypes with higher absolute WSI had increased iWUE. On the other hand, in summer, we observed a negative correlation between absolute WSI and iWUE $\left(\mathrm{iWUE}=62.708-0.178{ }^{*} \mathrm{WSI}\right)$, indicating that more stressed genotypes were not able to use water efficiently. We also observed a significant effect of taxa level in winter $\left(F=3.45, p=0.021, \mathrm{R}^{2}=0.13\right)$ and summer $\left(\mathrm{F}=5.85, p=0.001, \mathrm{R}^{2}=0.21\right)$. Only E. nitens was different at the slope coefficient, compared to E. globulus and E. gloni. In winter, we observed that the increase in iWUE with the increase in WSI was more pronounced in E. nitens (Figure 2a). The same was observed in summer, with a decrease in iWUE with an increase in WSI (Figure 2b).

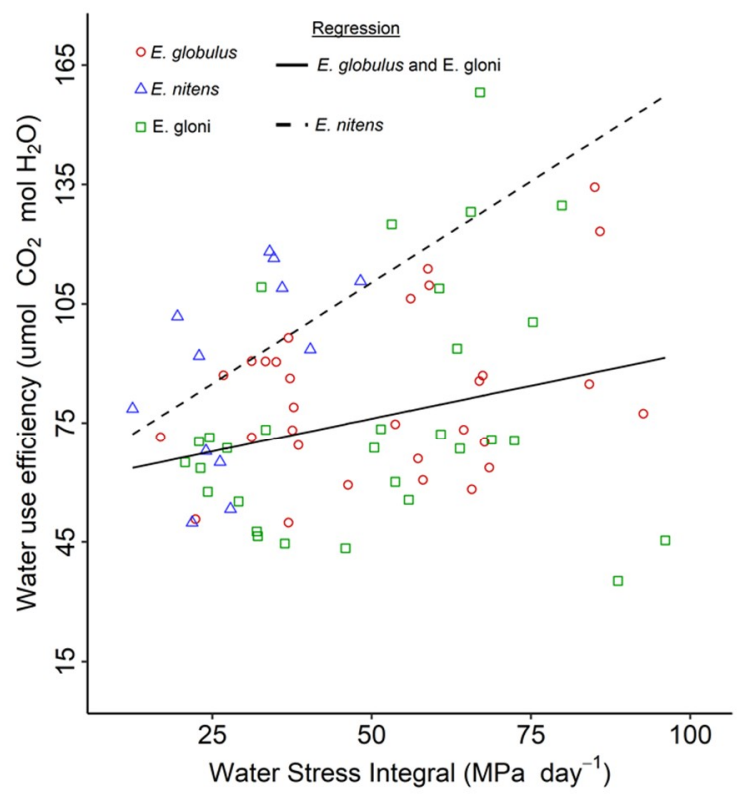

(a)

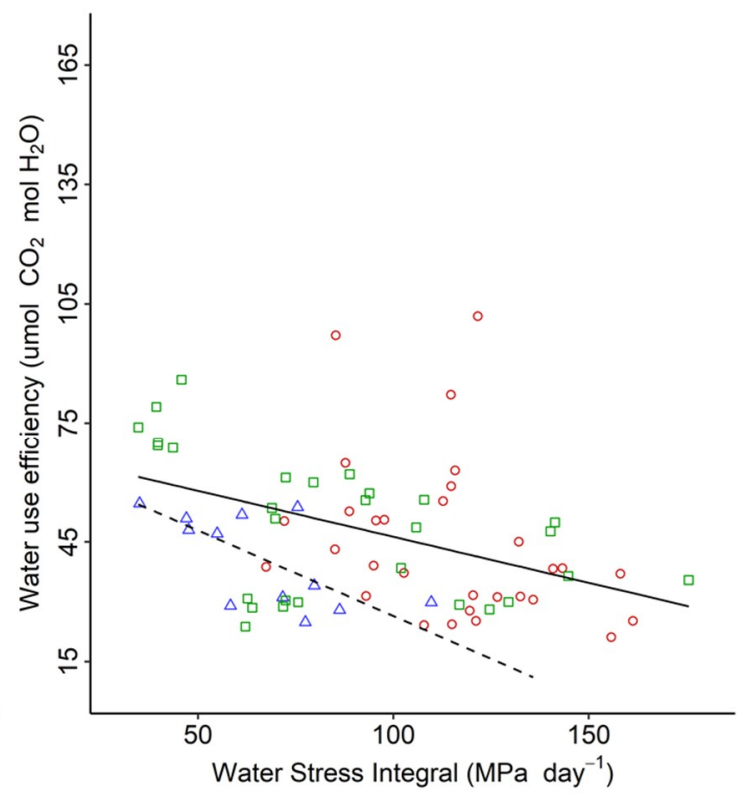

(b)

Figure 2. Adjusted regression lines for winter (a) and summer (b) periods for eucalyptus genotypes. 


\section{Discussion}

This study evaluated the changes in physiological variables in the early development of different eucalyptus genotypes during different seasons. A limited number of experiments have tested how genotypes physiological responses perform according to changes in temperature and atmospheric demand. This is very important considering that many studies have shown the importance of changes in temperature and atmospheric demand on forest development [12-14]. Similar to the study of Butnor et al. [15], small values of An were observed during winter (low temperatures), which suggested that cooler temperatures in winter affected plant metabolism.

Hikosaka et al. [16] observed that An and gs may increase or decrease if temperatures are below or above the optimum, consequently affecting iWUE. At the study site, the average optimum temperature for eucalyptus growth was $16{ }^{\circ} \mathrm{C}$ [2], which was observed in summer periods. Considering that the plants were well-watered, this could be the reason for the higher maximum An values in summer compared to winter for all taxa. However, An declined with maximum temperatures above $30^{\circ} \mathrm{C}$ [17], which suggested that maximum An is not stable during summer days. Negative relationship between temperature and An was observed by Aspinwall et al. [18], which suggested that eucalyptus responses reflect a common homeostatic constraint to seasonal changes in temperature.

The increase in gs values was also observed in summer periods, mainly because gs responded to the increase in photosynthetic active radiation (PAR), as always observed in summer months [19]. On the other hand, with an increase in gs, we observed a decrease in iWUE in summer, with higher atmospheric demand mainly for E. nitens (300\%). This was different from the results of other studies, which showed stomatal closure as the first physiological response to water stress [20]. This could be caused by lower soil water content or higher VPD. Lim et al. [21] highlighted that wet tropical eucalyptus plantations and well-watered experiments do not follow a pattern of strong VPD effect on gs and An reduction; these could be the reason why high VPD in summer did not present a reduction in gs values.

Larger values of WSI were observed among eucalyptus genotypes in winter periods, ranging from -12 to $-96 \mathrm{MPa}^{-1 a y^{-1}}$, and between -34 and $-181 \mathrm{MPa}^{-1 a y^{-1}}$ in summer. Different relationships between WSI and iWUE among seasons were observed, indicating a possible interaction effect of temperature and WSI in response to iWUE. In winter, genotypes with higher absolute WSI also presented higher iWUE. Higher values of leaf water potential, which increased WSI, acclimated genotypes to maintain lower stomatal conductance [22]; this was more pronounced in E. nitens. In contrast, in summer, stressed genotypes had lower iWUE, indicating higher water loss from the leaf due to stomatal opening. Differences in regression lines indicated that E. nitens was more physiologically sensitive to changes in WSI in both seasons, presenting higher stomatal control to limit water loss when cumulative water conditions were less favorable, as observed in the study of Gauhier and Jacobs [23] on Juglas nigra L trees. Future studies may provide drought responses during summer periods to observe that physiological variables will respond in a similar way when compared with well-watered treatments.

\section{Conclusions}

High incremental changes in photosynthesis were observed in summer months for almost all eucalyptus genotypes, showing its positive relationship with temperature in well-watered experiments. Because of irrigation during summer, soil water availability was not a constraint, and stomatal conductance followed photosynthesis behavior, decreasing intrinsic water use efficiency during periods of higher atmospheric demand when compared to winter. Significant relationships were observed between water stress integral and intrinsic water use efficiency in different seasons and taxa. We demonstrated that E. nitens was more sensitive to changes in water stress integral, and less tolerant to drought than E. globulus and E. gloni. 
Author Contributions: T.W.G.d.O. wrote the paper and analyzed the data; R.R. conceived and designed the experiments, and reviewed the paper; C.R.S. and A.P.D.C. reviewed the paper. All authors have read and agreed to the published version of the manuscript.

Funding: This work was supported by the government of Chile via FONDEF Project Number IT16I10087; Fondecyt Project 1190835, CMPC S.A. Co., ARAUCO S.A. Co., Bioforest S.A. Co., and Universidad de Concepción.

Acknowledgments: We gratefully acknowledge CMPC S.A. (Forestal Mininco) for supporting the field installations and establishment of irrigation systems, Forest Productivity Cooperative and University of Concepcion for supporting the fieldwork, and CNPq for the financial support for this study, for the Doctorate Researcher Scholarship of the first author.

Conflicts of Interest: The authors declare no conflict of interest.

\section{References}

1. Stape, J.L.; Binkley, D.; Ryan, M.G. Eucalyptus production and the supply, use and efficiency of use water, light and nitrogen across a geographic gradient in Brazil. For. Ecol. Manag. 2004, 193, 17-31, doi:10.1016/j.foreco.2004.01.020.

2. Watt, M.S.; Rubilar, R.; Kimberley, M.O.; Kriticos, D.J.; Emhart, V.; Mardones, O.; Acevedo, M.; Pincheira, M.; Stape, J.; Fox, T. Using seasonal measurements to inform ecophysiology: Extracting cardinal growth temperatures for process-based growth models of five Eucalyptus species/crosses from simple field trials. N. Z. J. For. Sci. 2014, 44, 1-11, doi:10.1186/s40490-014-0009-4.

3. White, D.A.; Crombie, D.S.; Kinal, J.; Battaglia, M.; McGrath, J.F.; Mendham, D.S.; Walker, S.N. Managing productivity and drought risks in Eucalyptus globulus plantations in south-western Australia. For. Ecol. Manag. 2009, 259, 33-44, doi:10.1016/j.foreco.2009.09.039.

4. Medlyn, B.E.; Duursma, R.A.; Zeppel, M.J.B. Forest proctivity under climate change: A cheklist for evaluating model studies. Wiley Interdiscip. Rev. Clim. Chang. 2011, 2, 332-355, doi:10.1002/wwc.108.

5. Rubilar, R.; Hubbard, R.; Emhart, V.; Mardones, O.; Quiroga, J.J.; Medina, A.; Valenzuela, H.; Espinoza, J.; Burgos, Y.; Bozo, D. Climate and water availability impacts on early growth and growth efficiency of Eucalyptus genotypes: The importance of GxE interactions. For. Ecol. Manag. 2020, 458, 117763, doi:10.1016/j.foreco.2019.117763.

6. $\quad$ Landsberg, J.; Waring, R. Water relations in tree physiology: Where to from here? Tree Physiol. 2017, 37, 1832, doi:10.1093/treephys/tpw102.

7. Chaves, M.M.; Maroco, J.P.; Pereira, J.S. Understanding plant responses to drought-From genes to the whole plant. Funct. Plant Biol. 2003, 30, 239-264, doi:10.1071/FP02076.

8. Navarrete-Campos, D.; Bravo, L.A.; Rubilar, R.; Emhart, V.; Sanhueza, R. Drought effect on water use efficiency, freezing tolerance and survival of Eucalyptus globulus and Eucalyputs globulus $\times$ nitens curttings. New For. 2013, 44, 119-134, doi:10.1007/s11056-012-9305-0.

9. Adams, H.D.; Zeppel, M.J.B.; Anderegg, W.R.L.; Hartmann, H.; Landhäusser, S.M.; Tissue, D.T.; McDowell, N.G. A multi-species synthesis of physiological mechanisms in drought-induced tree mortality. Nature 2017, 1, 1285-1291, doi:10.1038/s41559-017-0248-x.

10. Myers, B.J. Water stress integral: A link between short-term stress and long-term growth. Tree Physiol. 1989, 5, 207-218, doi:10.1093/treephys/5.2.207.

11. Wickham, H. Creat Elegant Data Visualisations Using the Grammar of Graphics; Spring: New York, NY, USA, 2016; Available online: https://ggplot2.tidyverse.org.

12. Almeida, A.C.; Landsberg, J.J.; Sands, P.J. Parameterisation of 3-PG model for fast-growing Eucalyptus grandis plantations. For. Ecol. Manag. 2004, 193, 179-195, doi:10.1016/j.foreco.2004.01.029.

13. Binkley, D.; Campoe, O.C.; Alvares, C.; Carneiro, R.L.; Cegatta, I.; Stape, J.L. The interactions of climate, spacing and genetics on clonal Eucalyptus plantations across Brazil and Uruguay. For. Ecol. Manag. 2017, 405, 271-283, doi:10.1016/j.foreco.2017.09.050.

14. Elli, E.F.; Sentelhas, P.C.; Freitas, C.H.; Carneiro, R.L.; Alvares, C.A. Assessing the growth gaps of Eucalyptus plantations in Brazil-Magnitudes, causes and possible mitigation strategies. For. Ecol. Manag. 2020, 451, 117464, doi:10.1016/j.foreco.2019.117464. 
15. Butnor, J.R.; Johnsem, K.H.; Anderson, P.H.; Hall, K.B.; Halman, J.M.; Hawley, G.J.; Maier, C.A.; Schaberg, P.G. Growth, Photosynthesis, and Cold Tolerance of Eucalyptus benthamii planted in the piedmont of North Carolina. For. Sci. 2018, 65, 59-67, doi:10.1093/forsci/fxy030.

16. Hikosaka, K.; Ishikawa, K.; Borjigidai, A.; Muller, O.; Onoda, Y. Temperature acclimtion of photosynthesis: Mechanisms involved in the changes in temperature dependence of photosynthetic rate. J. Exp. Bot. 2006, 57, 291-302, doi:10.1093/jxb/erj049.

17. Crous, K.Y.; Drake, J.E.; Aspinwall, M.J.; Sharwood, R.E.; Tjoelker, M.G.; Ghannoum, O. Photosynthetic capacity and leaf nitrogen decline along a controlled climate gradiente in provances of two widely distributed Eucalyptus species. Glob. Chang. Biol. 2018, 24, 4626-4644, doi:10.1111/gcb.14330.

18. Aspinwall, M.J.; Drake, J.E.; Campany, C.; Varhammar, A.; Ghannoum, O.; Tissue, D.T.; Reich, P.B.; Tjoelker, M.G. Convergent acclimation of leaf photosynthesis and respiration to prevailing ambient temperatures under current and warmer climates in Eucalyptus tereticornis. New Phytol. 2016, 212, 354-367, doi:10.1111/nph.14035.

19. Peri, P.L.; Arena, M.; Martínez Pastur, G.; Lencinas, M.V. Photosynthetic response to diferente light intensities, water status and leaf age of two Berberis species (Berberidaceae) of Patagonian steppe, Argentina. J. Arid. Environ. 2011, 75, 1218-1222, doi:10.1016/j.jaridenv.2011.06.003.

20. Flexas, J.; Bota, J.; Loreto, F.; Cornic, G.; Sharley, T.D. Diffuse and metabolic limitations to photosynthesis under drought and salinity in C3 plants. Plant Biol. 2004, 6, 269-279, doi:10.1055/s-2004-820867.

21. Lim, H.; Alvares, C.A.; Ryan, M.G.; Binkley, D. Assessing the cross-site and within-site response of potential production to atmospheric demand for water in Eucalyptus plantations. For. Ecol. Manag. 2020, 464, 118068, doi:10.1016/j.foreco.2020.118068.

22. Silva, M.A.; Jifon, J.L.; Santos, C.M.; Jadoski, C.J.; Silva, J.A.G. Photosynthetic capacity and water use efficiency in sugarcane genotypes subject to water deficit during early growth phase. Braz. Arch. Biol. Technol. 2013, 56, 735-748, doi:10.1590/S1516-89132013000500004.

23. Gauthier, M.M.; Jacobs, D. Photosynthetic parameters of Juglans nigra trees are linked to cumulative water stress. Can. J. For. Res. 2019, 49, 752-758, doi:10.1139/cjfr-2018-0355.

Publisher's Note: MDPI stays neutral with regard to jurisdictional claims in published maps and institutional affiliations.

(C) 2020 by the authors. Submitted for possible open access publication under the terms and conditions of the Creative Commons Attribution (CC BY) license (http://creativecommons.org/licenses/by/4.0/). 